\title{
Frequency and Pattern of Bronchiectasis in Patients with Chronic Obstructive Pulmonary Disease Presenting in a Tertiary Care Hospital
}

${ }^{1}$ Asifa Karamat, ${ }^{2}$ Huma Batool, ${ }^{3}$ Sohail Anwar, ${ }^{4}$ Shazia Akram, ${ }^{5}$ Atif Masood, ${ }^{5}$ Wajid Ali Rafai

${ }^{1}$ Department of Pulmonology, Gulab Devi Hospital, Lahore

${ }^{2}$ Department of Pulmonology, Lahore General Hospital, Lahore

${ }^{3}$ Department of Pulmonology, University of Lahore Teaching Hospital, Lahore

${ }^{4}$ Department of Pulmonology, Pakistan Atomic Energy Commission, Chashma

${ }^{5}$ Department of Medicine, University of Lahore Teaching Hospital, Lahore

\begin{abstract}
Introduction: Chronic Obstructive Pulmonary Disease (COPD) is a high burden respiratory issue all over the world. It has high morbidity and mortality in the United States. Bronchiectasis is associated with chronic obstructive pulmonary disease (COPD) and is under diagnosed as diagnostic tools like HRCT though easily available but an expensive test in developing countries like Pakistan. We aim to establish the frequency and patterns of bronchiectasis in patients of COPD.

Aims and Objectives: To establish the frequency and pattern of bronchiectasis in COPD in our population so that we can improve patient care and quality of life of these patients.

Place and duration of study: We did a cross sectional survey in Department of Pulmonology, Gulab Devi Hospital, Lahore. Study was completed from $1^{\text {st }}$ September 2017 to $28^{\text {th }}$ February 2018.

Material \& Methods: After taking an informed consent 150 already diagnosed COPD patients were included. Bronchiectasis was seen on high resolution CT scan (HRCT). Data was collected on a structured proforma and analyzed on SPSS version 20.

Results: Bronchiectasis was observed in $76(50.6 \%)$ patients of COPD while 74 patients had no bronchiectasis. Out of 76 , cylindrical bronchiectasis was seen in $82 \%$. Lower lobe and bilateral involvement was more common. Means of age, gender, exacerbations of COPD, and history of pulmonary tuberculosis were not related to bronchiectasis while pack years of smoking, duration of illness and Modified Medical Research Council (MMRC) Dyspnea Scale were significantly related to bronchiectasis.

Conclusion: This is observed that bronchiectasisis quite common (50.6\%) in patients of COPD in our population.
\end{abstract}

Key words: Bronchiectasis, Chronic obstructive pulmonary disease

\section{INTRODUCTION}

$\mathrm{C}$ hronic Obstructive Pulmonary Disease (COPD) is a high burden health issue globally. It is the $4^{\text {th }}$ major cause of morbidity and mortality in the United States, and according to recent data, it is projected to cause heavy burden of disease globally. ${ }^{1,2,3}$ Despite the diagnostic and therapeutic advancements the prevalence of respiratory diseases is increasing. ${ }^{1}$ The prevalence of COPD is around $14 \%, 7 \%$, and $3 \%$ in smokers, former smokers and non-smokers respectively. ${ }^{2}$ Recent studies have projected that worldwide heavy budget will be spent on respiratory disease by 2030 . In contrast, the per year will be the cost of smoking cessation program for controlling tobacco-related diseases is significantly low. $4,7,8,9,10$
Patients with COPD and bronchiectasis have more severe disease with poor outcome and higher frequency of exacerbations and complications. ${ }^{5}$ High resolution Computed Tomography (HRCT) is a good diagnostic tool for determining the extent and severity of bronchiectasis. ${ }^{6,11,12}$ In a quite a few studies bronchiectasis was found in more than 50\% of COPD patients. Cylindrical bronchiectasis was present in majority and cystic bronchiectasis in almost $20 \%$ of cases. Commonly lower lobes were involved. Mostly COPD patients have bilateral involvement with no specific segmental predominance. $^{7}$

Various patients factors influence the frequency of bronchiectasis among COPD patients, like mean smoking pack year, active smoking, duration of disease, number of exacerbations leading to hospital admission, MMRC score (Modified Medical 
Research Council Dyspnea Scale), past history of tuberculosis and degree of airway obstruction.?

We aim to establish the frequency and patterns of bronchiectasis in COPD patients of our population. By doing so, we can improve the patient care and management of these patients thus improving their quality of life and exacerbation rates.

\section{MATERIAL AND METHODS}

It was a cross-sectional study conducted in Gulab Devi Hospital, Lahore. Patients were labeled as having COPD on the basis of both of the following two criteria based on values of pulmonary function test (PFT's)

- Post bronchodilator FEV1 less than or equal to $80 \%$ with reversibility less than $15 \%$ or less than $200 \mathrm{ml}$.

- Post bronchodilator FEV1/ FVC, (forced expiratory volume in one second/forced vital capacity) less than 0.7 .

Bronchiectasis was diagnosed on the HRCT reported by consultant radiologist. The study was conducted in Department of Pulmonology, Gulab Devi Hospital, Lahore from $1^{\text {st }}$ September 2017 to $28^{\text {th }}$ February 2018.COPD patients with age $\geq 40 \&$ $\leq 80$ years were included in this. People with 15 pack year smoking history were considered as chronic smoker. ${ }^{8}$ Patient who were already diagnosed case of bronchiectasis were excluded from the study.

Sampling Technique was non-probability consecutive purposive sampling.

After taking informed consent from patient, data was collected. Pulmonary function tests (PFT's) was done to measure FEV1 and FVC in each patient (As per inclusion criterion). Demographic characteristics included in this study were height, age, BMI, sex, current or ex-smoking history, history of Huqqa smoking, pack year of smoking, number of COPD exacerbations in previous one year and past history of anti-tuberculous treatment, and exposure to biomass fuel. MMRC dyspnea scale was used to assess functional status.

HRCT was performed as per protocol was reported by same consultant radiologist. Presence of bronchiectasis as well as patterns of bronchiectasis was documented based on radiologist's report. Selection bias was addressed by using appropriate sample size and by using non-probability consecutive sampling. Measurement bias was addressed by using uniform measurement scale/units for each patient. Data was collected on a structured proforma (attached).

\section{Statistical analysis:}

Standard deviation and mean was taken of different variables i.e. BMI, age, no. of COPD exacerbations, smoking pack years, FVC, MMRC score, and No. of COPD exacerbations). Frequency and percentages were taken for variables i.e. history of $\mathrm{TB}$, gender, hukka smoker and biomass fuel exposure, current/Ex-smoker, and presence and pattern of bronchiectasis. SPSS 20 version was used for analysis of this study. Chi square and Fisher Exact Tests were applied.

\section{RESULTS}

Total 150 patients of mean age of $56.2 \pm 5.9$ years were included in the study. Characteristics of studied population are shown in table 1. According to findings there were $71 \%$ and $29 \%$ males and females respectively. Fifteen percent patients were previously treated for pulmonary tuberculosis. Half of the sampled population was exposed to cigarette and Huqqa. More than half of the patients (67\%) have stopped smoking for past 1 year. In last one year average number of exacerbations is $3.2 .50 \%$ of our study population had bronchiectasis. 14 patients $(18 \%)$ had cystic bronchiectasis while majority $(82 \%)$ had cylindrical bronchiectasis on HRCT. Most of the patients having bronchiectasis in current study population have multiple lobe involvement (n $=65,85 \%)$. Lower lobe was the common site involved. Majority $(n=48,64 \%)$ had bilateral involvement. (Table-2)

On comparison of groups with and without bronchiectasis there was non-significant difference of patients of bronchiectasis between ages more than and less than 60 years. Similarly gender is also found not related with bronchiectasis in studied sample, $p=0.14$. Mean number of exacerbations is same for both groups of patients, $p=0.24$ there was non-significant difference of patients of bronchiectasis between exacerbations more than and less than 3 per year $(p=0.1)$. But in bronchiectasis group, smoking years $(\mathrm{p}=0.03)$; time elapse since in years $(p=<0.001)$; and MMRC score $(p=<0.001)$ were significantly higher. It is seen that patients who had previously received antituberculous treatment were equally distributed in bronchiectasis and non-bronchiectasis groups $(\mathrm{p}=0.2)$. Similarly both ex-smokers and active were equally prone to develop bronchiectasis $(p=0.58)$ as shown in Table- 3 


\begin{tabular}{|l|l|}
\hline Mean Age & $56.2 \pm \mathrm{SD}$ \\
\hline Gender (\%) & \\
Male & $106 / 150(71)$ \\
Female & $43 / 150(29)$ \\
\hline Smoking status & \\
Cigarette smoker (\%) & $33 / 150(22)$ \\
Huqqa smoker (\%) & $13 / 150(9)$ \\
Cigarette + Huqqa Smoker (\%) & $69 / 150(46)$ \\
Biomass fuel exposure (\%) & $34 / 150(23)$ \\
Active smoker (\%) & $45 / 150(33)$ \\
Ex-smoker (\%) & $100 / 150(67)$ \\
\hline History of pulmonary tuberculosis (\%) & $22 / 150(15)$ \\
\hline Mean COPD exacerbation in last one year & $3.2 \pm 1.7$ \\
\hline Mean duration of smoking(years) & $41.3 \pm 18.9$ \\
\hline Mean MMRC score & $2.8 \pm 0.74$ \\
\hline Mean time elapsed since diagnosis (year) & $7.09 \pm 3$ \\
\hline Table-1: Basic demographics of study population (n=150)
\end{tabular}

\begin{tabular}{|l|l|}
\hline Bronchiectasis & \\
Present (\%) & $76 / 150(50.6 \%)$ \\
Absent (\%) & $74 / 150(49.3)$ \\
\hline Type of bronchiectasis & \\
Cystic (\%) & $14 / 76(18)$ \\
Cylindrical (\%) & $62 / 76(82)$ \\
\hline Extent of bronchiectasis & \\
One lobe & $11 / 76(15)$ \\
More than one lobe & $65 / 76(85)$ \\
Upper lobe & $11 / 76(15)$ \\
Lower lobe & $65 / 76(85)$ \\
Right lung & $10 / 76(12)$ \\
Left lung & $18 / 76(24)$ \\
Bilateral & $48 / 76(64)$ \\
\hline
\end{tabular}

Table-2: Frequency and characteristics of Bronchiectasis $(\mathrm{n}=150)$

\begin{tabular}{|l|c|c|c|}
\hline Parameter & $\begin{array}{c}\text { BronchiectasisBronchiectasis } \\
\text { present }\end{array}$ & $\begin{array}{c}\text { value } \\
\text { absent }\end{array}$ & \\
\hline Age & 48 & 50 & 0.7 \\
$<60$ years & 28 & 24 & \\
>60years & 50 & 57 & 0.14 \\
\hline Gender & 26 & 17 & \\
$\begin{array}{l}\text { Male } \\
\text { Female }\end{array}$ & & & \\
\hline $\begin{array}{l}\text { Time elapsed since } \\
\text { diagnosis } \\
\text { <5 years } \\
<5 \text { years }\end{array}$ & 1 & 50 & $<0.001$ \\
\hline Smoking status & 75 & 24 & \\
$\begin{array}{l}\text { Current smoker } \\
\text { Ex-smoker }\end{array}$ & 23 & 26 & \\
$\begin{array}{l}\text { Mean duration of } \\
\text { smoking }\end{array}$ & 53 & 48 & 0.2 \\
\hline Mean mMRC & 3 & 38 & 0.03 \\
\hline $\begin{array}{l}\text { History of pulmonary } \\
\text { tuberculosis }\end{array}$ & 15 & 2.6 & 0.001 \\
\hline $\begin{array}{l}\text { No. of exacerbation } \\
\text { last year } \\
<3\end{array}$ & & & 0.2 \\
\hline 3 & 46 & 55 & 0.1 \\
\hline T3 & 30 & 19 & \\
\hline
\end{tabular}

Table-3: Comparison of patient characteristics with and without bronchiectasis

\section{DISCUSSION}

In our study population COPD was unequally distributed in males and females $(71 \%$ in males \& $29 \%$ in females) likely because smoking is more prevalent in males while in another study by Aryals et all concluded COPD to becoming more prevalent in females causing increase mortality. ${ }^{15}$ Majority in our study though had quit smoking but were still having bronchiectasis $(67 \%)$, showing contribution of smoking on permanent lung damage. Biomass fuel exposure was common in females due to use of high carbon fuel in rural areas.

More than half of the study population was having bronchiectasis which was comparable to observation of Martínez-García MÁ et al. ${ }^{7}$ Although another study showed only $30 \%$ prevalence of bronchiectasis in COPD patients. ${ }^{13}$ The pattern and distribution of bronchiectasis found in our study was cylindrical affecting bilateral lower lobes which was consistent with Martínez-García MÁ et al observation. $^{7}$ Bronchiectasis was significantly related to time elapsed since diagnosis, smoking pack years and MMRC score of severity of COPD. While age, gender, history of pulmonary tuberculosis and recurrent exacerbations were not significantly related to bronchiectasis in patients with chronic obstructive pulmonary disease. Jin, Jianmin and $\mathrm{Yu}$, Wenling et al. also observed the same factors which had significant impact on prevalence of bronchiectasis. ${ }^{14}$

\section{CONCLUSION}

It is concluded that the frequency of bronchiectasis is quite high $(50.6 \%)$ in COPD patients of our population and it needs to be ruled out. Some COPD patients are, more susceptible to develop this complication.

\section{REFERENCES}

1. Decramer M, Janssens W, Miravitlles M. Chronic obstructive pulmonary disease. Lancet. 2012 Apr 7; 379(9823):1341-51.

2. Athanazio R. Airway disease: similarities and differences between asthma, COPD and bronchiectasis. Clinics (Sao Paulo). 2012 Nov; 67(11):1335-43.

3. The Global Strategy for the Diagnosis, Management and Prevention of COPD, Global Initiative for Chronic Obstructive Lung Disease (GOLD) 2011. Available from: http://www.goldcopd.org/.

4. Rosenbaum L, Lamas D. Facing a "slow-motion disaster" - the UN meeting on non-communicable diseases. N Engl J Med. 2011; 365(25):2345-48. 
5. O'Donnell AE. Bronchiectasis in patients with COPD: a distinct COPD phenotype? Chest. 2011 Nov; 140(5):1107-8.

6. Gupta PP, Yadav R, Verma M, Agarwal D, Kumar M. Correlation between high-resolution computed tomography features and patients' characteristics in chronic obstructive pulmonary disease. Ann Thorac Med. 2008 Jul; 3(3):87-93.

7. Martínez-García MÁ, Soler-Cataluña JJ, DonatSanz Y, Catalán Serra P, Agramunt Lerma M, Ballestín Vicente $J$, et al. Factors associated with bronchiectasis in patients with COPD. Chest. 2011 Nov; 140(5):1130-7.

8. Yu Liu, Meng Dai, Yufang Bi, Min Xu, Active Smoking, Passive Smoking, and Risk of Nonalcoholic Fatty Liver Disease (NAFLD): A Population-Based Study in China. J Epidemiol. 2013; 23(2): 115-121.

9. Launois C, Barbe C, Bertin E, Nardi J, Perotin JM, Dury S, et al. The modified Medical Research Council scale for the assessment of dyspnea in daily living in obesity: a pilot study. BMC Pulm Med. 2012 Oct 1; 12:61.

10. Hu G, Zhou Y, Tian J, Yao W, Li J, Li B, et al. Risk of COPD from exposure to biomass smoke: a metaanalysis. Chest. 2010 Jul; 138(1):20-31.

11. Goeminne P, Dupont L. Non-cystic fibrosis bronchiectasis: Diagnosis and management in 21st century. Postgrad Med J.2010Aug;86(1018):493-501

12. Javidan-Nejad C, Bhalla S. Bronchiectasis. RadiolClin North Am. 2009 Mar; 47(2):289-306.

13. O'Brien C, Guest PJ, Hill SL, et al. Physiological and radiological characterization of patients diagnosed with chronic obstructive pulmonary disease in primary care. Thorax 2000; 55:635-642.

14. Jin, Jianmin $\mathrm{MD}^{\mathrm{a}}$; Yu, Wenling $\mathrm{MD}^{\mathrm{b}}$; Li, Shuling $\mathrm{MM}^{\mathrm{b}}$; Lu, LijinMD ${ }^{\mathrm{a}}$; Liu, Xiaofang $\mathrm{MD}^{\mathrm{a}}$; Sun, Yongchang MDa, Medicine: July 2016 - Volume 95 Issue 29 - p e4219.

15. Aryal S, Diaz-Guzman E, Mannino DM. Influence of sex on chronic obstructive pulmonary disease risk and treatment outcomes. Int $\mathrm{J}$ Chron Obstruct Pulmon Dis. 2014; 9:1145-54.

\section{The Authors:}

Dr. Asifa Karamat

Assistant Professor,

Department of Pulmonology,

Gulab Devi Hospital, Lahore.

Dr. Huma Batool

Assistant Professor,

Department of Pulmonology,

Lahore General Hospital, Lahore.

Dr. Sohail Anwar

Assistant Professor,

Department of Pulmonology,

University of Lahore Teaching Hospital, Lahore.

Dr. Shazia Akram

Assistant Professor,

Department of Pulmonology,

Pakistan Atomic Energy Commission, Chashma.

Dr. Atif Masood

Associate Professor,

Department of Medicine,

University of Lahore Teaching Hospital, Lahore.

Dr. Wajid Ali Rafai

Senior Registrar,

Department of Medicine,

University of Lahore Teaching Hospital, Lahore.

\section{Corresponding Author:}

Dr. Sohail Anwar

Assistant Professor,

Department of Pulmonology,

University of Lahore Teaching Hospital, Lahore.

E-mail: sohail.anwar@ucm.uol.edu.pk 